\title{
Robots and Rodents: Children’s Inferences About Living and Nonliving Kinds
}

\author{
Jennifer L. Jipson \\ Susan A. Gelman
}

\begin{abstract}
This study tests the firm distinction children are said to make between living and nonliving kinds. Three, 4-, and 5year-old children and adults reasoned about whether items that varied on 3 dimensions (alive, face, behavior) had a range of properties (biological, psychological, perceptual, artifact, novel, proper names). Findings demonstrate that by 4 years of age, children make clear distinctions between prototypical living and nonliving kinds regardless of the property under consideration. Even 3-year-olds distinguish prototypical living and nonliving kinds when asked about biological properties. When reasoning about nonbiological properties for the full range of items, however, even 5-year-olds and adults occasionally rely on facial features. Thus, the living/nonliving distinction may have more narrow consequences than previously acknowledged.
\end{abstract}

Much work in cognitive development has investigated the distinctions children honor between living and nonliving kinds. Despite the quantity and quality of existing work on this topic, critical gaps exist in current understanding. One open question concerns how children reason about items that appear to straddle the boundary between animate and inanimate. In children's everyday lives, they are likely to encounter a wide variety of objects that test this boundary. Examining children's reasoning about the world in all its complexity is particularly important as today's society embarks on what Brooks (2002) terms the "robotics revolution." In our society, children maybe among the first to have extended contact with this new technology. Robotic toys are now widely available and range in sophistication from Tiger Electronics' "Poo-Chi" to Ugobe's "Pleo." In addition, roboticappliances are beginning to penetrate domestic markets (e.g., Roomba vacuum cleaner). Today's robots are often built with sensorimotor abilities (e.g., to sense obstacles), move autonomously, and can look quite lifelike. Exploring how children think about these "artificial creatures" has become a critical avenue for research.

Identifying objects, such as robots, that have characteristics from multiple domains is a means toward two more specific goals. First, we can examine specific features that may be relevant to children as they negotiate their understandings of the living/nonliving distinction. In addition, we can explore whether children's early discrimination of living and nonliving kinds involves a single categorical distinction between domains, or whether children reason about living and nonliving kinds in a more multifaceted way. For example, a child may know that an object is not alive, yet be willing to attribute other animate properties (e.g., emotions) to that object. Existing research on these two topics will be discussed. We begin, however, with a brief review of the distinctionschildren are known to make between living and nonliving kinds.

In some of the earliest work on children's ontologicalunderstandings, children often reported nonliving entities such as bicycles and clouds to be alive (Bullock, 1985; Carey, 1985; Laurendeau \& Pinard, 1962; Piaget,1929). There are several ways to interpret this result. One possible explanation is that children share adults'biological understanding of the concept of life, yetpossess incomplete knowledge about the world and therefore believe some nonliving entities to be alive. Another possibility, however, is that children and adults do not attach the same meaning to the term "alive" (Carely, 1985). Thus, asking children to judge whether particular items are or are not alive does not yield clearconclusions as to whether and on what bases children differentiate living from nonliving kinds.

Efforts to explore further children's ontological understandings have centered on children's reasoning about whether or not entities have specific properties. For example, numerous researchers report that children as young as 4 years of age differentiate between animals and artifacts in their attribution of such biological properties as eating, growing, and dying (Backscheider, Shatz, \& Gelman, 1993; Carey, 1985; Dolgin \& Behrend, 1984; Gelman, Spelke, \& Meck, 1983; Hatano et al., 1993; Inagaki \& Hatano, 1996; Jipson \& Callanan, 2003; Waxman, 2005). Children also provide different causal explanations for animals and artifacts with regard to movement (e.g., Gelman \& Gottfried, 1996; Massey \& Gelman, 1988) and other properties (e.g., Gottfried \& Gelman, 2005; Simons \& Keil, 1995; Springer \& Keil, 1991).

\section{Unresolved Questions}

The growing evidence that children differentiate living from nonliving kinds stands in sharp contrast to Piaget's (1929) early ideas about children's reasoning. However, it is premature to conclude that preschool 
children distinguish living and nonliving things as distinct ontological types, for several reasons: (a) the items included in most research paradigms do not reflect the diversity of children's realworlds, (b) attention to the particular features children use when making ontological distinctions is incomplete, and (c) an emphasis on children's reasoning about biological properties may overestimate their ability to make clear domain distinctions. A review of existing work that has addressed these concerns is provided below.

Items

One issue we examine is the selection of items about which children are asked to reason. In many studies, investigators ask children to reason about objects that are clearly classifiable as living (e.g., animals) or nonliving (e.g., chairs). In that research, it is not surprising that children as young as 4 years of age easily differentiate between living and nonlivingkinds (e.g., Rosengren, Gelman, Kalish, \& McCormick,1991; Springer \& Keil, 1991).

Other studies have examined everyday items that have mixed properties (e.g., a doll, which looks like a person yet is inanimate; a cloud, which is inanimate yet seems to move on its own). Although Laurendeau and Pinard (1962) had suggested that items such as clouds and bicycles pose difficulties for young children, preschool children refrain from attributing animal properties to dolls, puppets, or other animate-looking artifacts (Dolgin \& Behrend,1984; Freeman \& Sera, 1996; Gelman et al., 1983). However, children’scapacity to distinguish dolls, puppets, or telephones with faces from truly animate objects should not be surprising given that such items are relatively crudeapproximations of animate entities.

An alternative approach has been to examine children's interpretations of "minimalist" items: dots orblobs that move on a computer screen. In contrast to items such as dogs or chairs, which provide rich cuesabout the animacy distinction, minimalist items provide no static perceptual cues about the identity of items, so children are forced to rely on movement or relational cues to guide their interpretations. Interestingly, children are capable of treating these items asmore or less animate, depending on how they move(e.g., Opfer, 2002). Thus, these items again provide evidence that children can extend their knowledge of the animate/inanimate distinction to atypical examples. However, these studies still leave open the question of how children reason about items that provide a challenge to the usual animate/inanimate distinction.

Altogether, potentially confusing real-world objects have received little study. In the animal kingdom, for example, many animals (e.g., stick bugs) look inanimate. Likewise, artifacts contain significant variability. Keil, Greif, and Kerner (2007) argue that researchers examining children's domain understandings tend to underrepresent the heterogeneity of the artifact domain, instead using such simple, commonplace artifacts as hand tools and furniture.

Several studies have focused specifically on children's understanding of "intelligent artifacts," such as computers and robots. One early example of thisresearch comes from Carey (1985) who, as part of a larger study, examined what properties children attributed to a mechanical monkey that appeared to move on its own. Although some children "seemed confused about whether they were being probed about real monkeys or the toy itself," by age 7, children never judged the monkey to have animal properties (eats, sleeps, thinks, etc.).

More recent studies have found that children distinguish between living kinds and robotic artifacts. Fiveyear-olds report that people have brains, but thatrobots, computers, and dolls do not (Scaife \& Van Duuren, 1995). In another study, Subrahmanyam, Gelman, and Lafosse (2002) asked 3- and 4-year-old children to sort photographs of animals, simple artifacts, machines (including a computer and a robot), and plants according to whether or not they had certain animate properties (eats, talks, thinks/ remembers, feels emotions). Children primarily attributed these properties to animals and, in general, did not attribute them to simple artifacts or machines. Melson et al. (2005) went further by providing 7- to 15- year-old children with opportunities to play with an actual living dog and a robotic dog before being questioned about specific properties. Although children viewed the live dog as more likely than the robotdog to have biological properties and mental states, $21 \%$ said that the robot dog was alive and $74 \%$ said that it could feel happy.

The finding that children show some tendency to blur domains when considering robots is consistent with the findings reported by other researchers. Nigam and Klahr (2000) found that although mostchildren did not consider a robot to be alive, 30\% judged it to have emotions, $20 \%$ judged it to have cognitive abilities, and $10 \%$ judged it to have volition. Further, children in the study by Subrahmanyam et al.(2002) (discussed above) were willing to say that therobot could think and remember (see also Mikropoulos, Misailidi, \& Bonoti, 2003). Thus, by around 5 years of age children seem to have fairly clear understandings of the properties of computers, as evidenced by their reasoning about life status, biological properties, perceptual abilities, capacity for self-initiated 
movement, and psychological properties. However, when asked to consider robots, even school-aged children's reasoning was less predictable, often attributing living kind properties to robots. More research is needed to compare different kinds of items directly in the same research program.

Features

Closely linked to the question of which items children are asked to consider, is the question of which features differentiate such items. These are really two sides of the same coin. For example, including both animals and artifacts as two kinds of items is equivalent to varying the feature of animacy. It is therefore useful to consider which features might be relevant to children of different ages as they come to construct a concept of animates. A specific aim of this paper is to examine specific features of objects that may or maynot be relevant to children as they negotiate theirunderstandings of various living and nonliving objects.

Two attributes that have received significant attention in the literature are facial features and contingentresponse, both of which affect even infants' reactions (Johnson, Slaughter, \& Carey, 1998). Jones, Smith, and Landau (1991) found that 3-year-olds treated novel objects differently, depending on whether or not they had eyes. Thus, the presence of a face may affect children's thinking, but the extent of that impact is notknown. Another attribute that may be used by children to determine the life status of an object is that of autonomous behavior (Dolgin \& Behrend, 1984; Ochiai, 1989; Piaget, 1929; Sharp, Candy-Gibbs, \& Barlow-Elliott, 1985), especially goaldirected autonomous behavior (Opfer, 2002; Opfer \& Siegler, 2004).

\section{Properties}

Implicit in the work reviewed in the earlier sections (Items, Features) is the importance of considering a variety of properties when attempting to understand children's animacy concepts. For example, children sometimes judge a robot not to have biological properties, yet attribute psychological properties to it (e.g., Nigam \& Klahr, 2000; Subrahmanyam et al., 2002). Such results suggest that children do not make a singleuniform distinction when reasoning about ambiguous objects. Instead, their judgments differ depending on whether they are asked to reason about aliveness, biological properties, or psychological properties.

This result should come as no surprise given similar findings with regard to children's reasoning about animals. Although Carey (1985) reports that children demonstrate similar patterns of property attributions when reasoning about biological and psychological properties, more recent studies suggest that children differentiate biological from nonbiological properties (Coley, 1995; Inagaki \& Hatano, 1993; Inagaki \& Sugiyama,1988).

\section{Current study}

The current study extends current work on children's understanding of the distinction between living and nonliving objects in several ways. First, we ask how firm children's ontological distinctions are when they are asked to reason about varied aspects of the world. One way in which we pursue this question is by comparing children's reasoning about objects with clear category membership to objects with potentiallyambiguous category membership, including both artifacts and animals. At the same time, we investigatechildren's reasoning about a variety of object properties: biological, psychological, perceptual, and artifactproperties. Finally, we systematically vary a set of attributes that were hypothesized to influence children's category judgments: whether or not an object is alive, whether or not an object has a face, and whether or not an object demonstrates autonomous behavior.

\section{Method \\ Participants}

Fifty-two preschool-aged children participated in this study, including sixteen 3-year-olds $(M=3-8$,

range $=3-6$ to $4-0)$, twenty 4-year-olds ( $M=4-7$, range $=4-2$ to $4-11$ ), and sixteen 5-year-olds ( $M=5-6$, range $=5-1$ to $6-1$ ). Twenty undergraduate students also participated to fulfill a course requirement. There were equal numbers of males and females in each age group. The participants were predominantly European 
American and from middle-incomehomes. One additional 4-year-old and one 5-year-oldwere tested but excluded from the analysis because they had previously participated in a related study.

\section{Materials}

Stimuli

The items varied on the following dimensions: whether or not they were alive, whether or not they had a face, and whether or not they demonstrated autonomous behavior (Table 1). Because several of these items were likely to have been unfamiliar to children (e.g., starfish, sensor box), we selected itemsthat were atypical examples of even the familiar categories (e.g., a stuffed meerkat rather than a stuffeddog). Participants viewed six 30-s video clips depicting a male experimenter: (a) watching a rodent (a Chilean rat called a degu) move actively about a cageand touching the rodent's nose with his finger, (b) watching and pointing at a living green "brittle star"' (a marine organism that differs somewhat from the commonly known starfish in that it has five long slender flexible arms that radiate from the central body disk) actively move about a tank, (c) watching and interacting with a technologically advanced robotic dog (I-Cybie), (d) playing with a "sensor box"' (a specially constructed metal box that responded to motion and sound with lights and beeps), (e) playing with a stuffed animal (a meerkat), and (f) rolling a toycar (dune buggy) back and forth upon a table. All video clips were displayed on a laptop computer. In addition to the videos, ten 4- $\mathrm{x}$ 6-inch laminated color photographs were used. The photographs depicted each of the six items, as well as a dog, a cat, a radio, and a computer.

\section{Interview}

The interview developed for this study consisted of a set of 10 property projection questions and a naming question. Eight of the property projection questions focused on familiar properties from the following domains: biological (Does this one eat? Does this onegrow?), psychological (Can this one think? Can this one feel happy?), perceptual (Can this one see things? If I tickled this one would this one feel it?), and artifact(Did a person make this one? Can this one break?). The other two property projection questions asked about unfamiliar behaviors ('lolls,' 'croons') and unfamiliar internal parts ('spleen,' 'micron'). The naming question asked whether or not it would be okay to give each item a personal proper name.

\section{Procedure}

All participants were tested individually in a quietroom. Children participated during school hours at their preschool, and adults participated by appointment in a university laboratory. Participants viewed all six video clips in random order. Following each video, participants were asked the set of eight familiarproperty projection questions in random order. A second researcher recorded participants' responses, any pronouns that participants used as they discussed each item, and any spontaneous explanations participants may have provided.

After viewing all six videos and answering the familiar property questions, participants were asked two questions, in counterbalanced order, probing novel properties. In one question, the researcher showed the participants photographs of a cat and a radio. While pointing to the cat, participants were told, "This one lolls." While pointing to the radio, participants were told, "This one croons." Participants were then shown color photographs of each of the six items seen in the videos and were asked tojudge whether each item lolled like the cat or crooned like the radio (e.g., "Your job is to decide whether this one lolls/croons like this one, or croons/lolls like this one. What do you think?”). The order of presentation of the novel behavior was counterbalanced across participants within each age group, with some children hearing first that the cat lolls and other children hearing first that the radio croons. The second novel property projection question required participants toreason about an item's internal parts. The researchershowed participants color photographs of a dog and a computer. Participants were told, "This one has a spleen inside" (dog) and "This one has a micron inside" (computer). Again, participants were asked tojudge whether each of the six items had a spleen inside or a micron inside. In the adult interviews, the words "lolls" and "croons" were replaced by the novel words "daks" and "meeks" to address concerns that adults may have been familiar with the verbs loll and croon. Similarly, for adults the words "micron" and "spleen" were replaced with the words "modi" and "toma."

A final question asked participants to judge whether or not it would be okay to give each item a personal name. Participants were shown a photograph of a girl and a cup. The experimenter then explained, "Some things are 
okay to name, like this person, we could call her Sally. Other things shouldn'tget a name, like this cup. It wouldn't be okay to name a cup." The experimenter then showed participants a picture of each item and asked, "What do you thinkabout this one? Would it be okay or not okay (not okayor okay) to give this one a name?”

\section{Results}

Results are reported in four sections. The first section reports participants' responses to the familiar property projection questions. The second section reports results from the novel property projection questions. The third section reports the results from the naming question. The fourth section analyzes the pronouns produced spontaneously. Within each of these sections, we looked first at whether participants' responses differed significantly from what would be expected by chance. We then compared responses to examine whether participant age and question type influenced patterns of response for each item. Finally, we investigated whether participants used any systematic rules when reasoning about whether to attribute various properties to the target items.

\section{Familiar Properties}

Participants' responses to each of the familiar property questions were scored for the number of "yes" responses given as a function of question type(biological, psychological, perceptual, artifact) anditem. Recall that two familiar properties were probed for each of the four question types (e.g., for biologicalquestions we asked, "Does this one eat?" and “Does this one grow?"). As a result, scores for each questiontype could range from 0 (did not attribute either property to the item) to 2 (attributed both properties to the item). The mean numbers of “yes” responses given for each item by question type at each age areprovided in Table 2.

\section{Comparisons to Chance}

One-sample $t$ tests were used to compare the mean number of "yes" responses for each item (by questiontype) to chance levels of responding (i.e., $M$ of 1 ). Asindicated in Table 2, on the vast majority of items, adults' responses differed from chance performance in anticipated ways, for all items except the starfish. Five-year-olds also predominantly reasoned about the properties of the six test items in systematic andadult-like ways, responding at chance levels only when reasoning about the psychological properties of the starfish and robodog, and the perceptual abilities of the robodog. In contrast to the highly consistent response patterns of these two older groups, 3- and 4-year-olds often responded at chancelevels. As can be seen in Table 2, these younger groups display most consistency when reasoning about biological and (to a lesser extent) perceptual properties, and show least consistency concerning thestarfish and robodog, and the artifact properties.

\section{Investigation of Relative Differences}

A second approach taken in analysis of these datawas to investigate differences in how participants at each age reasoned about the properties of the targetitems. Scores were analyzed using a 4 (age: 3, 4, 5 years, adults) $\mathrm{x}$ 4 (question: biological, psychological, perception, artifact) x 6 (item: degu, starfish, robodog, sensor box, stuffed animal, toy car) mixed analysis of variance (ANOVA). Age was a between-subjects factor, and item and question were within-subjects factors. Main effects were found for question and item, $F(3,204)=47.70, p<$ $.001, \mathrm{~g}^{2}=.41$, and $\mathrm{F}(5,340)=79.84, \mathrm{p}<.001, \mathrm{~g}^{2}=.54$, respectively. (Consistent with Tabachnick and Fidell's [1989] suggestion that partial eta square is an appropriate alternate computation of eta square, all etasquared results reported here use the partial eta-squared formula [SSeffect/ (SSeffect + SSerror)]. All the twoway interactions were also significant at the $p<.001$ level:

Question $\times$ Age, $F(9,204)=16.13, r i^{2}=.42$; Item $\times$ Age, $F(15,340)=4.99,, \mathbf{j}^{2}=.18$; and Question $\times$ Item, $\mathrm{F}(15,1020)=108.17, \quad r i^{2}=.61$.

These main effects and interactions are best understood in light of a significant Age $\times$ Question $\times$ Iteminteraction, $F(45,1020)=5.17, p<.001, r i^{2}=.19$. Toexplore this interaction, we conducted separate 4 (question) $\times 6$ (item) repeated-measures ANOVAs for each age group. At all ages, the main effects forquestion and item were significant at ps <.05. The Question $x$ Item interactions were also each significant at ps $<.001$. 
Tukey's Honestly Significant Differences (HSD) post hoc analyses of the Question x Item interactions at each age are reported below as a function of question type. The systematic selection of items exhibiting different features (aliveness, face, behavior) allows us to make distinct contrasts. For example, comparing participants' responses to questions about the robodog to their responses to questions about the degu contrasts their reasoning about two things that have a face and exhibit autonomous behavior but vary on whether or not they are alive. Only the analyses corresponding to the contrasts of interest are reported. We were primarily interested in comparing participants' responses when only one targeted feature differed between two items. There were, however, two other comparisons that made conceptual sense to explore. First, comparison of participants' reasoning about the degu and car contrasts two items that differ on all three features examined; thus, we refer to this as a "clear contrast." Second, comparing the starfish to the robodog allows us to pit aliveness against having a face, which is a strong test of the weight that participants give each of these features. See Table 3 for the results of the post hoc comparisons of the contrasts examined in this study.

Biological questions. At all ages, participants clearlyresponded differently to the degu and the car (clearcontrast) when attributing biological properties (HSD, $\mathrm{p}<.05$ ). In addition, participants at each age were more likely to attribute biological properties to living than nonliving items: More biological properties were attributed to the degu than to the robodog, and more biological properties were attributed to thestarfish than to the sensor box (HSD, $\mathrm{p}<.05$ ). By 4 years of age, participants also attributed biological properties more to the starfish than to the robodog (HSD, $p<.05)$, that is, in the strong case when aliveness was pitted against having a face. However, although aliveness is an important factor at all ages indetermining which items are able to eat and grow, there is some evidence that children were also influenced by whether or not an object had a face. Specifically, although both the degu and the starfish are alive and demonstrate autonomous behavior, 4-yearolds were more likely to attribute biological properties to the degu. In addition, 3-year-old children were just as likely to attribute biological properties to the robodog, a nonliving object with a face, as to the starfish, a living object without a face. None of the other face contrasts yielded significant post hoc results on biological property projections, nor did any of the behavior contrasts.

Psychological questions. By 4 years of age, judgments of whether an object can think or feel happy are influenced by whether or not the object is alive. Participants in the three oldest groups attributed psychological properties more to the degu than to the car(HSD, $p<.05)$. Similarly, these participants were morelikely to say that the degu and starfish had psychological properties than the robodog and sensor box, respectively (all HSDs $p$ $<$.05). Psychological proper ties were not, however, linked exclusively to living kinds. Whether or not an object had a face was occasionally an influential feature. Four- and 5-yearold children, but not adults, attributed psychological properties more often to the robodog than to the sensor box. Four-year-olds also attributed psychological properties more to the degu than to the starfish. This pattern was also true of adults. Finally, when having a face was pitted against being alive, adults were the only participants to differentially attribute more psychological properties to the starfish than to the robodog.

Perceptual questions. At all ages, participants attributed perceptual capacities more frequently to the degu than to the car (HSD, $p<.05)$. By 4 years of age, children used aliveness as a cue to whether or notan item is likely to be able to see or feel a tickle, ascribing these perceptual properties more to the degu than to the robodog and more to the starfish than to the sensor box. Interestingly, children at all three ages also endorsed perceptual capacities more often for the robodog than for the sensor box. This suggests again that children's reasoning about perceptual properties is influenced by whether or not anobject has a face. Adults also showed some evidence of a face bias, attributing perceptual properties more to the degu than to the starfish, a pattern that was also true for 3-year-old children. Further, adults attributed more perceptual properties to autonomously behaving objects: They were more likely to say that the robodog and sensor box could see/feel a tickle than the stuffed animal and car, respectively. 
Artifact questions. With the exception of 3-year-oldchildren, participants in each age group attributed artifact properties (made by a person, breakable) more to the toy car than to the degu. They also attributed these properties more to the robodog than to either the degu or the starfish, and more to the sensor box than to the starfish. Thus, by 4 years of age, participants clearly found aliveness to be very pertinent to judgments about artifact properties. Although 3-year-olds did not make all these distinctions, they did consider the robodog to be more likely to have artifact properties than the degu.

\section{Rule-Use Analysis}

Another approach to analyzing these data is to identify individual participants' rule use. The advantage of this approach is that it permits us to determine whether the group-level results hold up when examining the strategies of individuals or are instead an artifact of averaging. Furthermore, this analysis permits us to determine the consistency with which participants follow certain strategies. To conduct these analyses, we examined participants' responses over all six items (degu, car, etc.) to each of the eight questions considered separately (e.g., “eat,' '“think”).

In investigating patterns of individual rule use, we chose to consider responses to each question separately. We obviously did not wish to collapse over all eight questions as different questions tap into different types of concepts (e.g., one would not expect thesame answers to biological questions as to artifact questions, so it does not make sense to create a single rule collapsing over those questions). Furthermore, collapsing over pairs of questions (e.g., "think" and "feel happy") leads either to overly strict criteria for rule use (perfect consistency over 12 trials-e.g., twopsychological questions $x$ six items) or to ambiguousresponses (e.g., intermediate between an alive rule and a "face" rule). Therefore, examining responses to all six items to each single question permits most responses to be classified into one or another rule, while still preserving rigorous criteria for use of a rule(as indicated by the low-chance probabilities of conforming to the target rules; see below).

We focused on four primary rules: alive (only livingkinds display the property: degu, starfish), face (onlyitems with faces display the property: degu, robodog, stuffed animal), movement (only items that move display the property: degu, robodog, starfish), and artifact (only nonliving kinds display this property: car, sensor box, robodog, stuffed animal). Although other rules were considered (e.g., all behaving items, all items without faces), they were not used more than two times and so were not considered further. The four primary rules were conceptually meaningful andused at least three times each. Because participants had a $50 \%$ chance of answering "yes" or "no" to eachitem and because each response pattern involved a unique combination of "yes" and "no" responses to the six items, the probability of displaying any particular pattern was $p=(.5)^{6}$ or .016 .

In addition, we calculated two more lenient rules: alive subset (at least one living kind and no nonliving items) and artifact subset (at least one artifact and no nonartifact). The probability of each of these rules ishigher than that for the rules above because they can be reached via a variety of paths. Specifically, the "alive subset" rule entails saying "yes" to only the rodent or to only the starfish; thus, the probability of displaying this rule is (.5) [no to robodog] x (.5) [no tostuffed animal] x (.5) [no to car] * (.5) [no to sensor box] x (.5) [yes to rodent or starfish, but not both], thusequaling .031. The "artifact subset" rule entails saying "yes" to at least one of the artifacts [robodog, stuffedanimal, sensor box, and car] but not all; thus, the probability of displaying this rule is (.5) [no to rodent] $\times(.5)$ [no to starfish] $\times(.875)$ [any combination of responses to the four artifact items except all yes or allno], thus equaling .22.

As can be seen in Table 4 (Panel a), a few major findings emerge from these analyses. First, over $60 \%$ of responses can be categorized into one of these sixrules, even though chance alone would allow only $31 \%$ to be classified as such. At the same time, consistent rule use increases dramatically with age: $37 \%$ of 3 -yearolds' responses could be classified intoone of the six major rules, 55\% of 4-year-olds' responses, $74 \%$ of 5 year-olds' responses, and $77 \%$ of college students' responses. It is interesting that consistent rule use is nearly as high at 5 years of age asit is among college students. The second major point is that alive and alive subset are the most common rules. Use of any particular feature (face or movement) was much less frequent, even among the youngest participants. Finally, it is clear that rules differ as a function of the question being asked (Table 4, Panel b). Theartifact rule was used exclusively for the questions regarding "make" and "break," and the artifact subset rule was used primarily for those questions as well. In contrast, the alive and alive subset rules werenever used for make or break, and were most consistently used for the other questions (especially "eat”).

\section{Novel Properties}


After responding to the familiar property questions for all six items, participants were asked two questions about novel properties. One question askedparticipants to decide whether each of the six items had internal parts associated with an animal (dog) or an artifact (computer). The other question asked participants to judge whether each item was likely to behave more similarly to an animal (cat) or an artifact (radio). On each question, participants were given a score of 1 for selecting the option associated with animals. Preliminary analyses revealed no significant differences involving property type, so responses to the two novel property questions were collapsed for the purposes of these analyses. Thus, composite scores could range from 0 (participant did not choose the property associated with the animal on either novel property questions) to 2 (participant chose the animal property on both questions). Eight children were dropped from this analysis because they refused to answer the novel property projectionquestions (two 3-year-olds, two 4-year-olds, and four 5 -year-olds). The mean number of animal-similar options selected by participants at each age is displayed in Table 2. Also depicted in Table 2 is whether or not participants at each age differed from chance(set at 1) in their attribution of animal-like novel properties to the six items.

Scores were submitted to a 4 (age) x 6 (item) mixedANOVA, which yielded a significant main effect of item, $F(5,300)=64.62, p<.001$, as well as a significantAge $x$ Item interaction, $F(15,300)=8.48, p<.001$. Follow-up repeated-measures ANOVAs for each agegroup determined that the effect of item was significant for 4-year-olds, 5-year-olds, and adults, $p<.001$.

As shown in Table 5, post hoc Tukey's HSD analyses examining the contrasts of interest for 4-yearolds, 5year-olds, and adults revealed that at each age participants judged the degu to have novel animalproperties more than they did the car. Four-year-old seemed to have many routes to deciding what properties to attribute to each item. They demonstrated sensitivity to aliveness in that they attributed animalproperties more to the degu and starfish than the robodog and sensor box, respectively. They were also,however, seemingly influenced by whether or not anitem had a face, attributing animal properties more to the stuffed animal than to the toy car. However, 4yearolds were also more likely to attach novel animal properties to the stuffed animal than to the robodog. This indicates an interesting reversal of the pattern seen in other analyses and raises the possibility that other unaccounted-for features might be playing a role in children's thinking about novel properties (e.g., texture). By 5 years of age, aliveness stood out as the mostimportant indicator of whether or not an item had novelanimal properties. Five-year-old children and adultsattributed animal properties more to the degu than to the robodog, more to the starfish than to the sensor box, and more to the starfish than to the robodog.

\section{Rule-Use Analysis}

Investigation of whether participants adhered to any specific rules when reasoning about novel properties followed the procedure described above for familiar property questions. Participants' use of each of the six rules (alive, face, movement, artifact, alive subset, artifact subset) in response to each novel property question is provided in Table 6. Roughly half of participants' responses were consistent with one of the six rules, with the alive rule being by far the most commonly used (36\%). Also of note is that whereas adults were fairly consistent in their responses, often using rules, children were less so.

\section{Name}

Our last question asked participants whether or not it would be okay to give each item a name. With the exception of one 3-year-old boy, all participants completed the interview through this question. Participants' responses were scored 1 for yes, and 0 for no(see Table 2 for means). Data were analyzed using a 4(age) x 6 (item) mixed-design ANOVA, with age as a between-subjects variable and item as a within-subjects variable. Results indicated a main effect foritem, $F(5,335)=48.25, \mathrm{p}<.001, \mathrm{~g}^{2}=.42$, as well as anItem $\mathrm{x}$ Age interaction, $F(15,335)=2.64, p<.01, g^{2}=.11$. To investigate this interaction, repeated-measures ANOVAs were performed for each age group separately. A main effect of item was significant at each age, ps $<.01$.

Tukey's HSD post hoc comparisons examining the target contrasts revealed that 3-year-old children did not differentiate between any of the items involved inthe specified contrasts with regard to naming. By 4 years of age, however, children did differentiate between the items involved in the clear contrast, moreoften reporting that a degu should receive a name than a toy car. Five-year-old children and adults alsoindicated an appreciation for the role of aliveness innaming, more often indicating that it was appropriate to name the starfish than the sensor box. Interestingly, however, they did not differentiate between the robodog and degu when reasoning about naming. This may be due to their additional concern about whether or not an object had a face. Participants at the oldest two ages suggested that it was okay to name the stuffed animal, but not a car; okay to name the robodog, but not the sensor box (all HSDs, $p<.05$ ). See Table 2 for a summary of these results. 
Rule-Use Analysis

Investigation of participants' use of the six rulesidentified previously revealed that very few participants seemed to follow a consistent pattern of response when reasoning about whether or not it was acceptable to give an item a name. This result stands in sharp contrast to analysis of individual rule use for familiar properties and, to a lesser extent, novel properties.

\section{Pronouns}

As a final measure of participants' reasoning abouta variety of living and nonliving items, we recorded the pronouns that participants spontaneously used as they discussed each item. Participants who used pronouns at all could refer to an item exclusively withgendered pronouns (e.g., "he" or "she"), exclusively with gender-neutral pronouns (e.g., "it" or "that"), with both gendered and gender-neutral pronouns, or with ambiguous or neither usage (e.g., "they”). Our investigation of participants' use of pronouns focused specifically on their use of the gendered pronouns (e.g., he, she, "his,' "“her[s]”).

For each participant, each item was scored with either a 1 (indicating that at least one gendered pronoun was used) or a 0 (indicating that no genderedpronoun was used). Overall, adults were quite conservative in their spontaneous use of gendered pronouns, using gendered pronouns for only $15 \%$ of items. In contrast, children often used these pronouns, with 5-year-olds using them in reference to $26 \%$ of the items, 4-year-olds in reference to $34 \%$ of theitems, and 3-year-olds in reference to $41 \%$ of the items. Scores were submitted to a 4 (age) x 6 (item) mixed ANOVA. Results indicated a significant item main effect, $F(5,340)=38.57, p<.001, g^{2}=.36$. Also significant was the Age $x$ Item interaction, $F(15,340)=3.07, p<.001, g^{2}=.12$. Separate ANOVAs confirmed that the effect of item was significant at each age at $p<.001$. See Table 7 for means.

Post hoc paired comparisons focusing just on the target contrasts were made using Tukey's HSD test with $p$ set at .05. As in the previous analyses, participants at each age reasoned differently about the deguand the toy car, using gendered pronouns more for thedegu. Interestingly, for participants of different ages, different features seemed to be at play in making thisdistinction. In all three of the comparisons involving face (robodog vs. sensor box, stuffed animal vs. car, degu vs. starfish), 3- and 4-year-old children demonstrated a consistent bias to refer to items with faces using gendered pronouns. Three-year-olds, but not 4- year-olds, also demonstrated this bias in the strong test case comparing the starfish to the robodog. Fiveyear-olds showed a similar, but less pronounced, pattern. At this age, children only differentiated between two of the face items, using he/she more for the robodog than the sensor box and more for thedegu than the starfish. None of the other paired comparisons for the 5-year-olds were significant. Finally, adults' pattern of response was quite different. Adults infrequently used gendered pronouns, and when they did so it was exclusively for the degu (seven adults) and starfish (one adult). Thus, the significant paired comparisons for adults were those involving the degu.

\section{Discussion}

The main question addressed in this work was whether and how preschool children differentiateliving from nonliving kinds. Our investigation of children's ontological distinctions reveals a complex developmental picture. The first major result is that when we consider just the prototypical living and nonliving things (degu vs. toy car), children as young as 3 years of age treat these items as clearly distinct onseveral measures, including biological and perceptualproperties, as well as pronoun use. By 4 years of age, children treat these items as clearly distinct on everymeasure. These findings are consistent with those of earlier work examining children's domain distinctions (e.g., Carey, 1985; Dolgin \& Behrend, 1984; Gelman et al., 1983). The present study extends beyond previous work, however, by revealing that the distinction holds for 3-year-olds' reasoning about perceptual properties, as well as in their spontaneous use of pronouns, and for 4-year-olds' reasoning abouteach of the dimensions under investigation. Taken together, these findings demonstrate that by the age of 3 years, children reason about prototypical living and nonliving kinds in clearly distinct ways.

The second major result is that, for biological properties, children honor a firm ontological distinctionbetween living and nonliving items, starting at 3 years of age and continuing through to adulthood. The distinction appears in the selected living/nonliving contrasts (by age 3), in comparisons to chance (by age5), and in rule-use analyses. Importantly, the living/nonliving distinction about biological properties holds not only for prototypical instances but also for children's reasoning about atypical items as well (e.g., robodog, starfish). That 3-year-olds grant more biological properties to the degu than to the robodog, and to the starfish than to the sensor box, reveals an 
early andstriking sensitivity to precisely the contrast of relevance to mature biological reasoners (i.e., adults). Similarly, that 4-year-olds grant more biological properties to the starfish than the robodog is especially impressive. Children were not misled into using face orautonomous movement for these judgments.

These clear distinctions, however, did not hold upwhen children were asked to reason about nonbiological features of the full range of items. For example,3-year-old children did not differentiate between the degu and the toy car on psychological or artifact properties, novel properties, or naming. Although 4- year-olds consistently distinguished between the degu and the toy car on all dimensions, they also relied on facial features when making psychological,perceptual, and novel property judgments. Even 5- year-olds and adults occasionally relied on facial features for psychological and perceptual judgments. Perhaps most strikingly, participants at all ages usedfacial features when determining whether an objectshould receive a proper name or receive a gendered pronoun. At no age did participants consistently use the living/nonliving distinction for these judgments.

Thus, the use of multiple measures to investigate children's (and adults') reasoning revealed clear differentiation between living and nonliving kinds on some measures (prototypical instances or biological features, or both) and lack of differentiation on others (especially atypical instances, when the questions concerned psychological properties or naming/pronoun use). These findings suggest that young children's animate/inanimate distinction is strongest in the biological realm. Once the questions extend beyond biological properties, the living/nonliving distinction no longer consistently governs children's reasoning.

What are the implications of these findings for a full view of the living/nonliving distinction in children's thought? First, the living/nonliving distinction is real, is more robust than previously established (extending to atypical instances), and is consistent by 3 years of age for biological and perceptual properties. Moreover, from 4 years onward, ourparticipants used life as the most consistent basis of their judgments (even more than face or autonomous behavior) for the property types probed, even when the reasoning task was complicated by asking participants to consider objects with less clear category membership. For example, participants at all ages used life as a decisive factor in making biologicaljudgments, with all but the 3-yearolds doing so even in the strong test when the robodog was compared to the starfish (i.e., a living thing without a face was compared to a nonliving object with a face). Participants continued to make psychological, perceptual, and artifact property attributions based primarily on whether or not an item was alive. This result also heldup in the rule-use patterns.

Second, however, the living/nonliving distinction is of narrower interest - to children or adults - than previous research would have led us to believe. That is, the living/nonliving distinction is somewhat domain limited. Although children possess a clearbasis on which to decide which things possess biological properties, they choose not to use this basis exclusively when reasoning beyond that domain. This result cannot be attributed to the idiosyncracies of a given item (e.g., thinking that perhaps a starfishcannot see because it does not have eyes), as the pattern held up for both perceptual and psychologicalproperties. One intriguing possibility is that childrenand adults may reason differently about animals at different points along the phylogenetic scale (Carey, 1985) —at least concerning nonbiological properties.

Third, there is an early capacity to distinguish biological from psychological properties. For example, although 4-year-old children rarely attributed biological properties to the robodog, they often maintained that the robodog possessed psychological andperceptual abilities. This conclusion is consistent withColey's (1995) claims regarding distinctiveness of these domains early in development and (importantly) extends Coley's findings (which were with kindergartners) to children as young as 3 years of age. The perspective that an item that is not alive can have psychological properties may be surprising to adults. We usually reason about items as having both biological and psychological properties (e.g., people, animals) or as being biological but not psychological (e.g., plants). The present data suggest that, for children, items can be nonbiological, but psychological. Thus, although participants at all ages seem to consider the biological domain to be distinct from other domains, the particular ways in which domainsinteract may be influenced by age and experience.

Fourth, language may be particularly blurring of the boundaries between living and nonliving. The cases where people were least likely to use the living/nonliving distinction and most likely to use other features (most typically, facial features) was in language: use of proper names and gendered pronouns. At first this seems quite sensible. After all, we all know of instances where proper names are extended to nonliving entities (boats, hurricanes) and so too forgendered pronouns (boats, countries). That children as well as adults showed these behaviors on our tasksis, thus, not particularly surprising. However, it points to a paradox that is deserving of further study. For it is by means of language that children most fullylearn about the world around them. As many have pointed out, children rely not just on their own observations to learn about the world but also 
crucially on the testimony of others (Harris \& Koenig, 2006). It is this testimony that contributes to children'sinsights about whole realms of knowledge, including nonobvious biological processes, others' mental andperceptual states, kinship relations, and so forth. The fact that the very language used to convey such information to children is so blurred makes it all themore remarkable that 3-year-olds honor a clean living/nonliving distinction when reasoning about biological properties. Indeed, we would propose that the problem is even deeper than this. It is not just proper naming and pronoun usage that blurs the distinction for children: The very nouns and verbs we usemix biological and nonbiological uses. The “dead" car battery, "'growing”' crystal, or "'lively" painting presents misinformation to a literal child. Somehow, though, children are not easily misled by such uses.

Although the findings provide new insights into the development of children's living kind concepts, there are also limitations to the work that should be addressed in future studies. First, the use of an interview technique in which we did not specifically ask participants to justify their responses leaves openthe possibility that children (or adults) may have interpreted some of the questions metaphorically (e.g., asserting that a car "eats" because it takes in gasoline; or asserting that the robodog "sees" because it senses objects in its environment). As noted earlier, there was little evidence for metaphorical interpretations of the biological questions (concerning eat andgrow), as participants at all ages honored a clearliving/nonliving distinction with such items. However, metaphorical interpretations may account for some of the responses to the sensory and psychological questions. This might account for some of the "noise" in the adult data (e.g., endorsement of sensory and psychological capacities for the robodog and sensor box). In future work, one could follow up more closely on such responses to try to determine whetherthey are intended as literal or metaphorical.

A related concern is that the use of spedific properties provides only indirect evidence regarding participants' beliefs about the general dimensions of interest. Participants may reject the specific properties under consideration here but still endorse the generalclass of properties of this type. For example, a child may believe that a starfish cannot feel a tickle but can feel pain. The present data should, therefore, be considered a conservative estimate of children's endorsements.

A third methodological consideration was the use of video demonstrations of movement. We chose to use video demonstrations for two reasons. First, thestimuli presented to children in prior studies tended to be static drawings or photographs. Such stimuli areimpoverished compared to the richness of cues available when actually interacting with an object or observing more dynamic representations of items, such as videos. Thus, on the one hand, asking children to reason about video demonstrations is an improvement over prevailing methods. On the other hand, werecognize that actually interacting with an object would have provided the richest experience. Past research suggests that even young children may be sensitive to subtle aspects of item movement in making life judgments (e.g., Opfer, 2002), so that being able to view the movement up close may helpchildren as they try to reason about the ontological status of these items. Due to the use of two live animals, however, such a procedure was impractical. Nonetheless, children's overall strong performance suggests that the use of videotapes did not pose an obstacle to children's understanding and may in fact have revealed earlier competence than prior work.

In conclusion, our data confirm the finding of paststudies that preschool children readily distinguish animate from inanimate entities when making biological judgments. Surprisingly, this is the case even with items that press the boundaries (e.g., robotic dogs, faceless starfish). At the same time, however, children display more mingling of the domains when reasoning about other sorts of properties, especially psychological properties. These results suggest that the living/nonliving distinction may have more narrow consequences than had previously been believed. Children (and to some extent adults) seem to maintain a degree of openness regarding the boundaries of the domain, an openness that is responsive to the discoveries of science (e.g., weird undersea creatures) and the inventions of people (e.g., robotic pets). This combination of ontological firmness and conceptual openness serves children well as they maneuver their way about an everchanging world.

\section{References}

Backsheider, A., Shatz, M., \& Gelman, S. (1993). Preschoolers' ability to distinguish living kinds as a function of regrowth. Child Development, 64, $1242-1257$.

Brooks, R. (2002). Flesh and machines: How robots will changeus. New York: Pantheon Press.

Bullock, M. (1985). Animism in childhood thinking: a newlook at an old question. Developmental Psychology, 21, $217-225$.

Carey, S. (1985). Conceptual change in childhood. Cambridge, MA: MIT Press.

Coley, J. (1995). Emerging differentiation of folkbiology and folkpsychology: Attributions of biological and psy-

chological properties to living things. Child Development, 66, 1856-1874.

Dolgin, K., \& Behrend, D. A. (1984). Children’s knowledge about animates and inanimates. Child Development, 55, $1546-1650$. 
Freeman, K. E., \& Sera, M. D. (1996). Reliance on visual and verbal information across ontological kinds: What do children know about animals and machines? Cognitive Development, 11, 315-341.

Gelman, R., Spelke, E. S., \& Meck, E. (1983). What preschoolers know about animate and inanimate objects. In D. Rogers \& J. Sloboda (Eds.), The development of symbolic thought (pp. 297-328). London: Plenum.

Gelman, S. A., \& Gottfried, G. M. (1996). Children's causalexplanations for animate and inanimate motion. ChildDevelopment, 67,1970-1987.

Gottfried, G. M., \& Gelman, S. A. (2005). Developing domain-specific causal-explanatory frameworks: The role of insides and immanence. Cognitive Development, 205,137-158.

Harris, P. L. \& Koenig, M. A. (2006). Trust in testimony: How children learn about science and religion. Child Development, 77, 505-524.

Hatano, G., Siegler, R. S., Richards, D. D., Inagaki, K., et al.(1993). The development of biological knowledge: A multinational study. Cognitive Development, 8, 47-62.

Inagaki, K., \& Hatano, G. (1993). Young children’s understanding of the mind-body distinction. Child Development, 64, 1534 $-1549$.

Inagaki, K., \& Hatano, G. (1996). Young children's recognition of commonalities between animals and plants. Child Development, 67, 2823-2840.

Inagaki, K., \& Sugiyama, K. (1988). Attributing human characteristics: Developmental changes in over and underattribution. Cognitive Development, 3, 55-70.

Jipson, J., \& Callanan, M. (2003). Mother-child conversation and children's understanding of biological and non-biological changes in size. Child Development, 74, 629- 644.

Johnson, S. C., Slaughter, V., \& Carey, S. (1998). Whose gaze would infants follow: The elicitation of gaze following in 12month-olds. Developmental Science, 1, 233-238.

Jones, S. S., Smith, L. B., \& Landau, B. (1991). Object properties and knowledge in early lexical learning. ChildDevelopment, 62, 499-516.

Keil, F. C., Greif, M. A., \& Kerner, R. S. (2007). A worldapart: How concepts of the constructed world are different in representation and in development. In E. Margolis \& S. Laurence (Eds.), Creations of the mind: Essays on artifacts and their representation (pp. 231-248). Oxford, UK: Oxford University Press.

Laurendeau, M., \& Pinard, A. (1962). Causal thinking in the child: A genetic and experimental approach. New York: International Universities Press.

Massey, C. M., \& Gelman, R. (1988). Preschooler's ability to decide whether a photographed unfamiliar object can move itself. Developmental Psychology, 24, 307-317.

Melson, G. F., Kahn, P. H. Jr., Beck, A. M., Friedman, B., Roberts, T., \& Garrett, E. (2005). Does AlBO have a soul?Children's perceptions of robotic dogs. Presented at the Biennial Meeting of the Society for Research in Child Development, Atlanta, GA.

Mikropoulos, T. A., Misailidi, P., \& Bonoti, F. (2003). Attributing human properties to computer artifacts: Developmental changes in children's understanding of the animate-inanimate distinction. Psychology: The Journal of the Hellenic Psychological Society, 10, 53 - 64.

Nigam, M. K., \& Klahr, D. (2000). If robots make choices, arethey alive? Children's judgments of the animacy of intelligent artifacts. Paper presented at the Twenty Second Annual Meeting of the Cognitive Science Society, Philadelphia.

Ochiai, M. (1989). The role of knowledge in the development of the life concept. Human Development, 32, 72 - 78.

Opfer, J. E. (2002). Identifying living and sentient kinds from dynamic information: The role of goal-directed versus aimless autonomous movement in conceptual change. Cognition, 86, 97-122.

Opfer, J. E., \& Siegler, R. S. (2004). Revisiting the livingthings concept: A microgenetic study of conceptual change in basic biology. Cognitive Psychology, 49, 301- 332.

Piaget, J. (1929). The child's conception of the world. London: Routledge and Kegan Paul.

Rosengren, K. S., Gelman, S. A., Kalish, C. W., \& McCormick, M. (1991). As time goes by: Children’s early understanding of growth in animals. Child Development, 62, 1302-1320.

Scaife, M., \& Van Duuren, M. A. (1995). Do computers have brains? What children believe about intelligent artifacts. British J ournal of Developmental Psychology, 13, 321-432.

Sharp, K. C., Candy-Gibbs, S., \& Barlow-Elliott, L. (1985). Children's judgment and reasoning about aliveness: Effects of object, age, and cultural/social background. Merrill-Palmer Quarterly, 31, 47-65.

Simons, D., \& Keil, F. C. (1995). An abstract to concrete shift in the development of biological thought: The insides story. Cognition, 56, $129-163$.

Springer, K., \& Keil, F. C. (1991). Early differentiation of causal mechanisms appropriate to biological and non-biological kinds. Child Development, 62, 767-781.

Subrahmanyam, K., Gelman, R., \& Lafosse, A. (2002). Animate and other separably moveable things. In G. Humphreys (Ed.), Category-specificity in brain and mind (pp. 341-371). London: Psychology Press.

Tabachnick, B., \& Fidell, L. (1989). Using multivariatestatistics. New York: Harper \& Row.

Waxman, S.R. (2005). Why is the concept "Living Thing” so elusive? Concepts, languages, and the development of folkbiology. In W. Ahn, R. L. Goldstone, B. C. Love, A. B. Markman, \& P. Wolff (Eds.), Categorization inside andoutside the laboratory: Essays in honor of Douglas L. Medin (pp. 49-67). Washington, DC: American Psychological Association. 
Table 1

\begin{tabular}{lcccccc}
\hline Items and Associated Features & & \multicolumn{3}{c}{ Items } \\
\cline { 5 - 6 } & & & & & \\
Feature & Degu & Starfish & Robodog & Stuffed animal & Sensor box & Toy car \\
\hline Alive? & Yes & Yes & No & No & No & No \\
Face? & Yes & No & Yes & Yes & No & No \\
Autonomous behavior? & Yes & Yes & Yes & No & No \\
\hline
\end{tabular}

Table 2

Mean Number of "Yes" Responses (each out of 2, with the exception of name, which is out of 1 )

\begin{tabular}{|c|c|c|c|c|c|c|}
\hline & Biological & Psychological & Perceptual & Artifact & Novel & Name \\
\hline \multicolumn{7}{|l|}{ 3-year-olds } \\
\hline Degu & $1.44 *$ & 1.31 & $1.50 *$ & $0.50 *$ & 1.21 & 0.73 \\
\hline Starfish & 1.13 & 1.00 & 0.94 & 0.69 & 1.21 & 0.40 \\
\hline Robodog & 0.63 & 1.31 & $1.38 *$ & 1.31 & 1.21 & 0.67 \\
\hline Stuffed animal & $0.56^{*}$ & 1.06 & 0.94 & 0.88 & 0.86 & 0.53 \\
\hline Sensor box & $0.25 *$ & 0.81 & 0.63 & 1.25 & 0.71 & 0.27 \\
\hline Car & $0.19 *$ & 0.69 & $0.16^{*}$ & 0.94 & $0.57^{*}$ & 0.27 \\
\hline \multicolumn{7}{|l|}{ 4-year-olds } \\
\hline Degu & $1.50 *$ & $1.50 *$ & $1.60 *$ & $0.20 *$ & $1.72 *$ & 0.70 \\
\hline Starfish & 0.90 & 0.80 & 1.15 & $0.30 *$ & 1.28 & 0.50 \\
\hline Robodog & $0.10^{*}$ & 0.85 & 0.90 & 1.15 & 0.78 & 0.55 \\
\hline Stuffed animal & $0.20 *$ & 0.65 & $0.50 *$ & 0.90 & $1.50 *$ & 0.50 \\
\hline Sensor box & $0.10 *$ & $0.20 *$ & $0.10^{*}$ & 1.05 & $0.50^{*}$ & $0.20 *$ \\
\hline Car & $0.00 *$ & $0.25 *$ & $0.20 *$ & 1.05 & $0.50 *$ & $0.20 *$ \\
\hline \multicolumn{7}{|l|}{ 5-year-olds } \\
\hline Degu & $1.81 *$ & $1.69 *$ & $1.94 *$ & $0.13^{*}$ & $2.00 *$ & $0.94 *$ \\
\hline Starfish & $1.75^{*}$ & 1.38 & $1.44^{*}$ & $0.25 *$ & $1.92 *$ & $0.81 *$ \\
\hline Robodog & $0.19 *$ & 0.88 & 0.69 & $1.81 *$ & 0.75 & $0.88 *$ \\
\hline Stuffed animal & $0.19 *$ & $0.44 *$ & $0.38^{*}$ & $1.50^{*}$ & 0.92 & $0.81 *$ \\
\hline Sensor box & $0.06^{*}$ & $0.19 *$ & $0.00 *$ & $1.56^{*}$ & $0.17^{*}$ & $0.13 *$ \\
\hline Car & $0.00 *$ & $0.13 *$ & $0.06 *$ & $1.56^{*}$ & $0.10^{*}$ & $0.19 *$ \\
\hline \multicolumn{7}{|l|}{ Adults } \\
\hline Degu & $1.90 *$ & $1.70^{*}$ & $2.00 *$ & $0.75 *$ & $2.00 *$ & $1.00^{*}$ \\
\hline Starfish & $1.95 *$ & 1.00 & 1.20 & 0.90 & $2.00 *$ & $1.00 *$ \\
\hline Robodog & $0.00 *$ & $0.15^{*}$ & $0.45^{*}$ & $2.00 *$ & $0.10^{*}$ & $0.95 *$ \\
\hline Stuffed animal & $0.00 *$ & $0.00 *$ & $0.00 *$ & $1.85^{*}$ & $0.15^{*}$ & $1.00 *$ \\
\hline Sensor box & $0.05^{*}$ & $0.15^{*}$ & $0.35 *$ & $2.00 *$ & $0.05^{*}$ & $0.20 *$ \\
\hline Car & $0.00 *$ & $0.00 *$ & $0.00 *$ & $2.00 *$ & $0.10^{*}$ & $0.20^{*}$ \\
\hline
\end{tabular}

*Significantly different from chance, $p<.05$, by t test.

Table 3

Post Hoc Comparisons for Familiar Properties (targeted contrasts only)

Property type

\begin{tabular}{|c|c|c|c|c|}
\hline $\begin{array}{l}\text { Biological } \\
\text { Contrast }\end{array}$ & $3-4-5-A$ & $\begin{array}{l}\text { Psychological } \\
3-4-5-A\end{array}$ & $\begin{array}{l}\text { Perceptual } \\
3-4-5-A\end{array}$ & $\begin{array}{c}\text { Artifact } \\
3-4-5-\mathrm{A}\end{array}$ \\
\hline
\end{tabular}

Clear 


\begin{tabular}{|c|c|c|c|c|}
\hline Degu (d) vs. car (c) & dddd & -ddd & dddd & $-\mathrm{ccc}$ \\
\hline \multicolumn{5}{|l|}{ Alive } \\
\hline Degu (d) vs. robodog (r) & dddd & -ddd & -ddd & rrrr \\
\hline Starfish (s) vs. sensor box (b) & s s s s & - sss & - sss & $-b b b$ \\
\hline \multicolumn{5}{|l|}{ Face } \\
\hline Robodog (r) vs. sensor box (b) & ----- & $-r r-$ & $\operatorname{rrr}-$ & --- \\
\hline Stuffed animal (a) vs. car (c) & ---- & ---- & ---- & ---- \\
\hline Degu (d) vs. starfish (s) & $-\mathrm{d}--$ & $-d-d$ & $\mathrm{~d}--\mathrm{d}$ & ---- \\
\hline \multicolumn{5}{|l|}{ Behavior } \\
\hline Robodog (r) vs. stuffed animal (a) & ---- & ---- & $---r$ & --- \\
\hline Sensor box (b) vs. car (c) & ---- & ---- & $---b$ & --- \\
\hline \multicolumn{5}{|l|}{ Alive/face } \\
\hline Starfish (s) vs. robodog (r) & - sss & $---s$ & $---s$ & $-\operatorname{rr}$ \\
\hline
\end{tabular}

Note. A letter indicates that the contrast was significant by Tukey’s HSD at $p<.05$. The precise letter specifies which item in the contrast had the higher mean number of "yes" responses.

Table 4

Rule-Use Analysis: Proportion of Familiar Property Questions on Which Participants Displayed Each Rule (a) by Age; (b) by Question

$\frac{\text { Alive }}{\text { Alive }^{\mathrm{a}} \text { Subset }^{\mathrm{b}} \text { Move }^{\mathrm{a}} \text { Face }^{\mathrm{a}} \text { Artifact }^{\mathrm{a}} \text { Subset }^{\mathrm{c}} \text { Otherd }}$

\begin{tabular}{llllllll}
$\begin{array}{l}\text { (a) } \\
\text { 3 years }\end{array}$ & .08 & .09 & .02 & .02 & .02 & .14 & .63 \\
4 years & .16 & .14 & .06 & .03 & .04 & .12 & .45 \\
5 years & .34 & .06 & .13 & .01 & .12 & .08 & .27 \\
$\quad$ Adult & .44 & .16 & .030 & & .13 & .01 & .23 \\
(b) & & & & & & & \\
Eat & .60 & .21 & .060 & & 0 & 0 & .14 \\
Grow & .53 & .07 & .010 & & 0 & .04 & .35 \\
Tickle & .36 & .19 & .080 & & 0 & .03 & .33 \\
See & .18 & .14 & .15 & .04 & 0 & .03 & .46 \\
Think & .24 & .19 & .08 & .04 & 0 & .03 & .42 \\
Happy .17 & .15 & .07 & .03 & 0 & .04 & .54 \\
Make & 0 & 0 & 0 & .01 & .51 & .19 & .29 \\
Break 0 & & 0 & 0 & 0 & .10 & .32 & .58 \\
\hline
\end{tabular}

${ }^{\mathrm{a}} p_{5} .02 .{ }^{\mathrm{b}} p_{5} .03 .{ }^{\mathrm{c}} p_{5} .22 .{ }^{\mathrm{d}} p_{5} .69$.

Table 5

Post Hoc Comparisons for Novel Animal Properties, Naming, and Gendered Pronoun Use (targeted contrasts only)

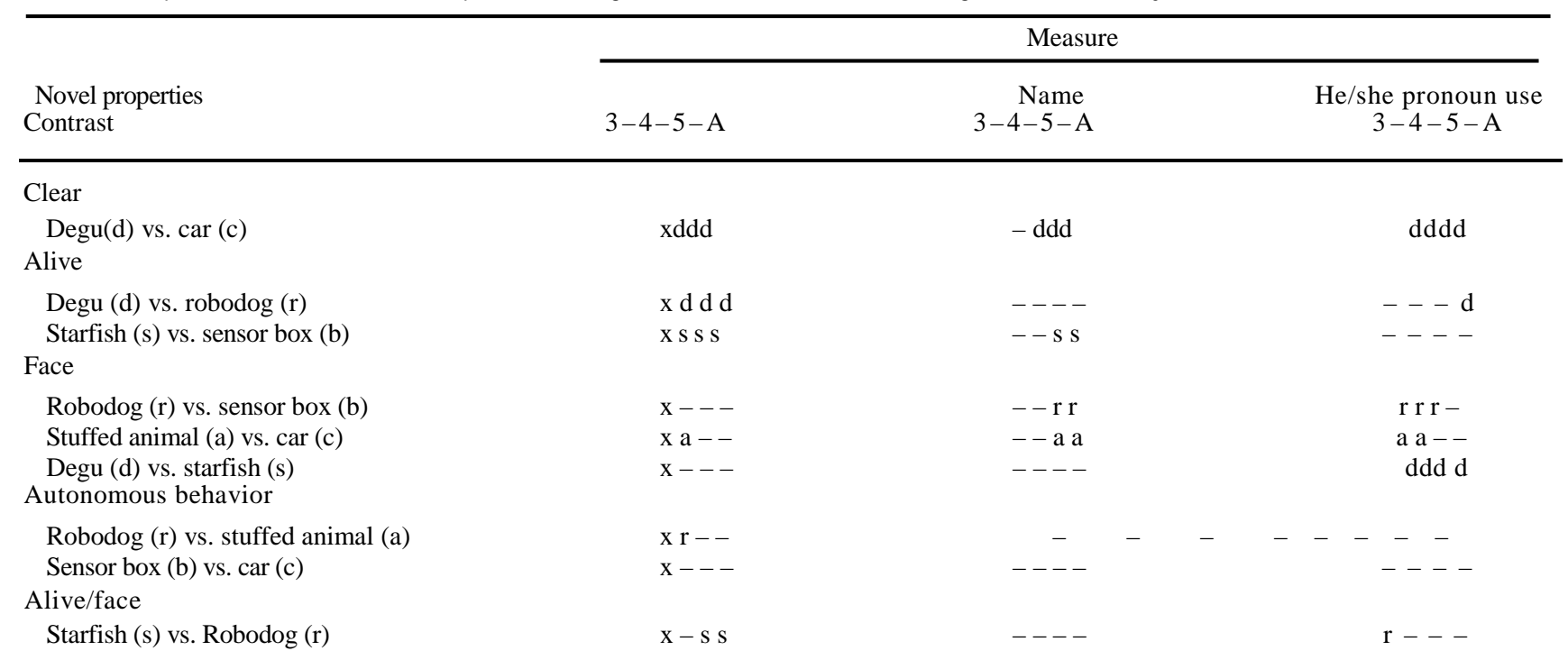


Note. A letter indicates that the contrast was significant by Tukey's HSD at $p<.05$. The precise letter specifies which item in the contrast had the higher mean number of "yes" responses. An x indicates that post hoc contrasts were not explored because the initial analysis of variance did not find significant main effects at these ages.

Table 6

Rule-Use Analysis: Proportion of Novel and Naming Property Questions on Which Participants Displayed Each Rule (a) by Age; (b) by Question

Alive Artifact

Alive $^{\mathrm{a}}$ Subset $^{\mathrm{b}}$ Move $^{\mathrm{a}}$ Face $^{\mathrm{a}}$ Artifact $^{\mathrm{a}}$ Subset $^{\mathrm{c}}$ Other $^{\mathrm{d}}$

\begin{tabular}{llllllll}
\hline (a) & & & & & & & \\
3 years & 0 & .02 & 0 & .09 & 0 & .07 & .82 \\
4 years & .14 & .02 & 0 & .07 & 0 & .07 & .70 \\
5 years & .22 & 0 & .05 & .02 & 0 & .02 & .68 \\
$\quad$ Adult & .62 & 0 & 0 & 0 & 0 & 0 & .38 \\
$\begin{array}{l}\text { (b) } \quad \\
\quad \text { Novel behavior }\end{array}$ & & & & & & & \\
$\quad$ Novel internal & .38 & 0 & .06 & 0 & .03 & .52 \\
$\quad$ part & .02 & .02 & .03 & 0 & .03 & .54 \\
$\quad$ Name & .06 & 0 & .01 & .04 & 0 & .06 & .82 \\
\end{tabular}

${ }^{a} p=.02 .{ }^{b} p=.03 .{ }^{c} p=.22 .{ }^{d} p=.69$.

Table 7

Mean Proportion of Participants Who Spontaneously Used a Gendered Pronoun (he/she) at Least Once, for Each Item

3-year-olds 4-year-olds 5-year-olds Adults

\begin{tabular}{lllll}
\hline Degu & .81 & .75 & .56 & .35 \\
Starfish & .31 & .35 & .19 & .05 \\
Robodog & .75 & .55 & .44 & .00 \\
Stuffed animal & .56 & .35 & .31 & .00 \\
Sensor box & .00 & .05 & .00 & .00 \\
Car & .00 & .00 & .06 & .00 \\
\hline
\end{tabular}

